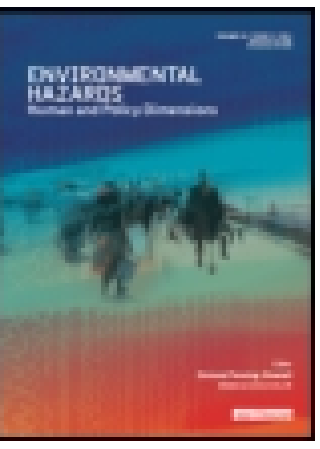

\title{
Environmental Hazards
}

\section{Civil society mobilisation after Cyclone Tracy, Darwin 1974}

\section{John Handmer \& Pascale Maynard}

To cite this article: John Handmer \& Pascale Maynard (2020): Civil society mobilisation after Cyclone Tracy, Darwin 1974, Environmental Hazards, DOI: 10.1080/17477891.2020.1838254

To link to this article: https://doi.org/10.1080/17477891.2020.1838254

View supplementary material $₫$

曲 Published online: 12 Nov 2020.

Submit your article to this journal $\pi$

Џll Article views: 50

Q View related articles $\sqsubset$

View Crossmark data \lceil 


\title{
Civil society mobilisation after Cyclone Tracy, Darwin 1974
}

\author{
John Handmer ${ }^{\mathrm{a}, \mathrm{b}}$ and Pascale Maynard ${ }^{\mathrm{b}}$

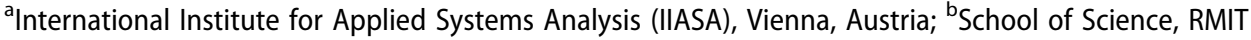 \\ University, Melbourne, Australia
}

\begin{abstract}
Major disasters challenge or exceed the capacity of the official emergency management sector to provide needed rescue services, support and relief. Emergency services in most jurisdictions do not have the surge capacity for unusual or extreme events without drawing on other jurisdictions or local people from outside the formal emergency management organisations. In such circumstances, those in the affected area need to organise themselves and make maximum use of local resources to cope with the immediate aftermath of impact. To find the required surge capacity, this suggests a whole of society response with the official system working with the capacities of people, commerce and organisations outside the emergency sector. An example is provided by the destruction of the northern Australian capital city of Darwin by Cyclone Tracy in December 1974. Informal volunteering and emergent leadership in Darwin and across Australia were critical to the immediate response and relief. Volunteering was widespread and worked well alongside official emergency management. With today's information and communication technologies and a strong national resilience narrative, we would expect to do at least as well. However, governments now exercise much more control over civil society. We examine the implications for surge capacity and adaptability.
\end{abstract}

\section{ARTICLE HISTORY}

Received 20 July 2020

Accepted 6 October 2020

\section{KEYWORDS}

Cyclone Tracy; Darwin, spontaneous volunteers; civil society mobilisation; surge capacity

\section{Introduction}

Large scale disasters challenge societies worldwide, and response is typically characterised as at best satisfactory, and at worst creating a humanitarian disaster. This is the case regardless of how wealthy the country concerned is - as the unfortunate experiences of New Orleans following Hurricane Katrina in 2005 (Handmer, 2006), and Puerto Rico following Hurricane Maria in 2017, demonstrate. The challenge for the affected communities and the officials responsible for emergency management, is heightened when there are many casualties, general destruction of the built infrastructure and severe on-going disruption of its associated functions and local livelihoods. These issues are exacerbated where the affected area is remote from needed resources. Even where resources are at hand, the destruction and immediate needs can overwhelm the capacity to restore assets, services and livelihoods. In these circumstances, those in the affected area need 
to rely on themselves and make maximum use of local resources to cope with the immediate aftermath of impact.

Assistance from outside the affected area, including international support and military forces, is costly and takes time. This time is often critical in terms of rescuing people trapped or injured by the event. Typically, local people are the first responders acting as informal emergency service volunteers, often filling the gaps between the initial impact and arrival of official responders, whether from the local area or outside (Scanlon et al., 2014; Whittaker et al., 2015; Twigg \& Mosel, 2017). It is important to appreciate that while official assistance is generally welcomed and expected, it can also displace local initiatives. While official or formal emergency services are usually held responsible for managing emergencies by the media and politicians (Handmer \& Dovers, 2013), they rarely have the capacity for unusual, extreme or long-lasting events. To find the required surge capacity, the capacities of people, businesses and organisations outside the emergency sector need to be harnessed. In other words, a whole of society approach is needed, while ideally emergency services act in a coordinating rather than command and control role (Quarantelli, 1998).

There are documented cases where the civilian population has mobilised in disasters triggered by natural phenomena, for example some 10 percent of Mexico City's population worked in the response to the 1984 earthquake (Twigg \& Mosel, 2017). As with other clear-cut examples, this case is some time ago which raises the question about whether there would be similar responses today. There are recent high profile cases where such positive and effective mobilisation does not appear to have occurred (with recent US cases provided above), and despite the historic cases set out in Twigg and Mosel (Twigg \& Mosel, 2017), well documented examples where the surge capacity inherent in most communities has been harnessed successfully at a city level are rare. Contemporary cases of response to city wide destruction are generally characterised by a strong top-down approach by government (Dionisio \& Pawson, 2016). However, one case of widespread mobilisation is provided by the destruction of the northern Australian territory capital city of Darwin by Cyclone Tracy in December 1974.

The case of Cyclone Tracy is examined in this paper in two parts: the first part examines the mobilisation of Darwin and the rest of Australia following the cyclone; and the second part reflects on what this historic case reveals about todays arrangements for civil society mobilisation. It sets out the approach taken, the context of the city of Darwin in 1974 and Cyclone Tracy before examining the local and national response. After discussing the response, the paper examines what factors make it more or less likely that such surge capacity would be harnessed as effectively today: does the current Australian approach to governance enable or restrict this kind of surge capacity? And are emergency management arrangements, attitudes and culture making it harder for civil society mobilisation to happen? We could reasonably expect that in an era with a strong narrative of shared responsibility and resilience, combined with the near universality of mobile technologies and social media, it would now be much easier and quicker for civil society to organise. This is in contrast to the early 1970s where long-distance communication was by expensive land lines and fixed phones, and where there was no government driven push for greater resilience. However, there are now also counter trends which may result in restrictions on informal mobilisation. This is one value of a historic case: to help inform our 
understanding of current trends and arrangements, and how these might be impacting emergency management capacity

\section{Approach}

After some initial research into Cyclone Tracy and guided by the Australian Bushfire \& Natural Hazards Cooperative Research Centre (BNHCRC) project on informal volunteering, we focused on three main questions: how widespread was informal volunteering? How quickly did this volunteering occur? What sort of issues and problems arose for the volunteers, the overall response and the impacted community? By addressing these we expect to be able to answer the broader question of whether similar surge capacity would be likely today, and how it might be better supported in today's context.

Using desktop research, largely qualitative information was compiled via the internet and library collections. The main sources were a mix of first-hand accounts in books, interviews, magazines and mainstream media, and media reporting at the time of the cyclone. This was significantly augmented by interviews and publications decades after the event. Some on-line collections of Cyclone Tracy material were also consulted. Darwin and Australian newspapers at the time of Tracy were examined, and a data base of specific examples to illustrate the role of the informal volunteers in the immediate response and relief after Cyclone Tracy hit Darwin was compiled. Newspapers, provided by the State Library of Victoria, were a primary resource that revealed the widespread nature of the volunteering. It became apparent that there was an Australia-wide response to Cyclone Tracy - both in terms of official agencies and processes, and informal community mobilisation. Research into informal (or spontaneous) volunteering is challenging as by their nature the activities are often short-term and the volunteers and any emergent groups, organisations or leadership, can vanish as needs are met (Strandh \& Eklund, 2017). One result is that information will inevitably be partial, in contrast to the formal system where decisions and activities are typically recorded in detail. A detailed time line produced as part of the study is appended as supplemental data.

\subsection{Terminology}

A range of terms are used to identify the type of volunteers we are primarily concerned with. These include: informal, unaffiliated, non-traditional, spontaneous, emergent, unofficial (Mclennan et al. this issue of Environmental Hazards) (Whittaker et al., 2015); and when widespread the term 'community mobilisation' is often used. In the case of Cyclone Tracy in Darwin clear distinctions are difficult to make, as ultimately we are concerned with the mobilisation of the civil society in Darwin to assist with response and immediate relief, as well as the partial mobilisation of civil society across Australia. The various terms have in common that the volunteers are not acting on behalf of a formal organisation, or if they are it is in a temporary volunteer capacity. In terms of the four part classification often used to categorise volunteering organisations (Dynes \& Quarantelli, 1968), those Darwin volunteers affiliated with non-emergency organisations would be 'expanding' their existing roles or 'extending' into new areas of activity. 


\subsection{Informal volunteers and surge capacity}

Australian authorities have developed guides and protocols for informal or 'spontaneous volunteers' in emergencies (AIDR, 2017), but are generally managing the issue of surge capacity in two main ways: by working to formalise the informal through pre-registration and checking for potential informal volunteers [eg (McLennan et al., 2016)]; and through drawing on Australian military and on the emergency services of other jurisdictions both domestic and international (Hellyer, 2020) - thereby acting to discourage informal volunteers. Contemporary publications on surge capacity are primarily concerned with how formal and official organisations can increase their capacity without involving civil society (eg. the 2015 'Surge transformation' report). In part this internal approach is driven by the increasing need for specialist skills and liability for health and safety and child protection (Austin \& O'Neill, 2015).

\section{Darwin and Cyclone Tracy}

The city of Darwin is located in the tropics at latitude 12 degrees south, well within the tropical cyclone zone, on the coast of the Timor Sea/Arafura Sea (Figure 1). It is the

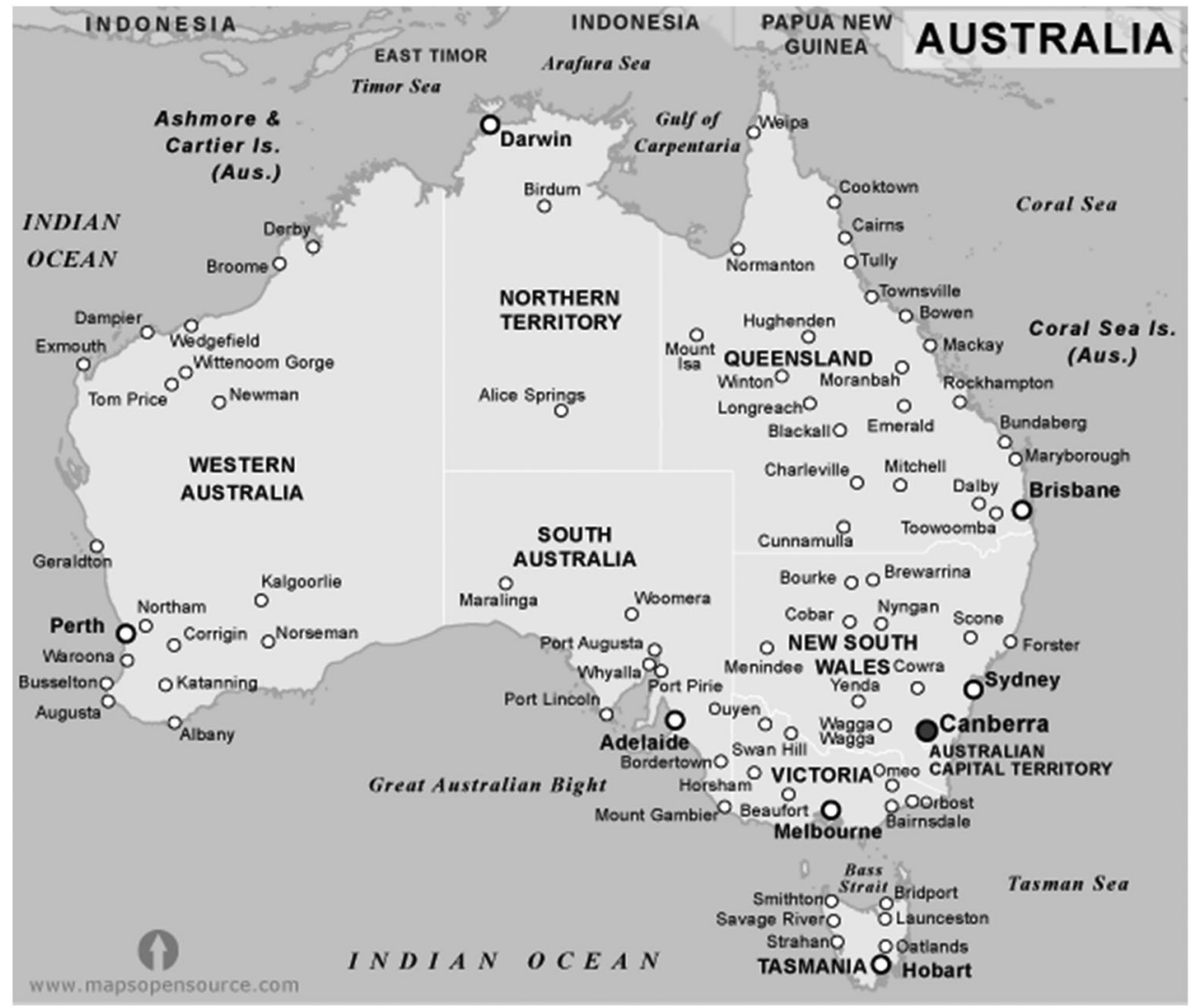

Figure 1. Location of Darwin, Alice Springs and Adelaide. Source: MapsOpenSource. Creative Commons 3.0. https://www.mapsopensource.com/australia-political-map-black-and-white.html 
most northerly Australian city, and capital of the Northern Territory (NT), which at the time of Cyclone Tracy was administered by the Australian national government in Canberra, with limited self-government granted in 1978. The city was a federal government outpost with the majority of the workforce employed directly or indirectly by the federal government. Its emergency management was within the purview of the newly created NDO (Natural Disasters Organisation) Australia's national emergency management body operating as part of Defence (now Emergency Management Australia in the Department of Home Affairs). There were also strong mining, construction, agriculture and tourism sectors. It has been argued that the small population remaining in Darwin after the cyclone's impact promoted more inclusion of the Indigenous community, of the Larrakia people, than before the cyclone (Haynes et al., 2011). At the time it was thought that the indigenous community had early warning of the cyclone through traditional knowledge. A recent news report appears to corroborate this (Liston \& La Canna, 2014).

At the time of Cyclone Tracy the population of Darwin was about 47,000. Today there are about 150,000 living in Darwin. The city is a very isolated place in terms of distance from Australian centres, being about 3000 kms by road from Adelaide, the nearest metropolitan centre, with Townsville, the nearest city about 2,500kms away. The central Australian town of Alice Springs is about $1500 \mathrm{kms}$ to the south. Darwin is however closer to East Timor and Indonesia at about $700 \mathrm{kms}$. In 1974 there was no rail link south to Alice Springs and much of the road from Alice Springs to Adelaide was an unsealed earth track. The road north of the rail head in Alice Springs was sealed in WWII to aid military transport, while the rail link was completed in 2004. Darwin has been damaged to near destruction on four occasions: the cyclones of 1897, 1937 and 1974 and by wartime bombing in 1942 .

Due to Darwin being on the site of Australia's most northerly major harbour it has long been a cosmopolitan port, at least in terms of 1970s Australia, with a significant Chinese population (Jones, 2005). Nevertheless, $70 \%$ of the 47,000 population in 1974 consisted of male civil-servants who were on short term postings, thus the core permanent population was only 8,000 (Taylor \& Carson, 2018). The predominantly male population at the time has been viewed as representing a 'frontier demography' (Carson, 2011); perhaps reflected in the 'women and children first' approach to the evacuation. The population was relatively young, and engaged through active participation in schools, clubs and outdoor activities. Most of the residential housing was typical for tropical and sub-tropical Australia: lightweight single story structures raised about one story above ground level.

\subsection{Cyclone Tracy}

As the Northern Territory lies near the equator, cyclones tend to form near the coast. This reduces the potential warning time and makes early detection and prediction critical. The monsoon, and cyclone season, runs from December through to March.

Early on 25 December 1974 (Christmas day) Darwin was hit with what is still considered Australia's most destructive cyclone (Handmer et al., 2018). Cyclone Tracy was first detected in the Arafura Sea on the 20th December. Late on the 21st it was named as a cyclone. It moved slowly, passing close to Bathurst Island. General warnings had been issued at this point (Stretton, 1977). Late on December 23rd it turned unexpectedly south-easterly towards Darwin, and at about midday on Christmas Eve a warning that 
Darwin was under threat was issued. The cyclone eye was about $6 \mathrm{~km}$ across and went directly over Darwin (Figure 2). The highest wind speed measured was $217 \mathrm{~km} / \mathrm{h}$. but the measuring instruments failed at that point. There are estimates that speeds were much higher, and that while generally classed as a Category 4 cyclone, it may have been a Category 5 just before impact (https://www.abc.net.au/news/emergency/201412-24/cyclone-tracy/5981404). There was no significant storm surge or prolonged heavy rain: the damage and loss of life was entirely the result of wind. Cyclone Tracy is now considered a 'midget' cyclone being the second smallest tropical storm recorded (Insurance Coouncil of Australia, 2019).

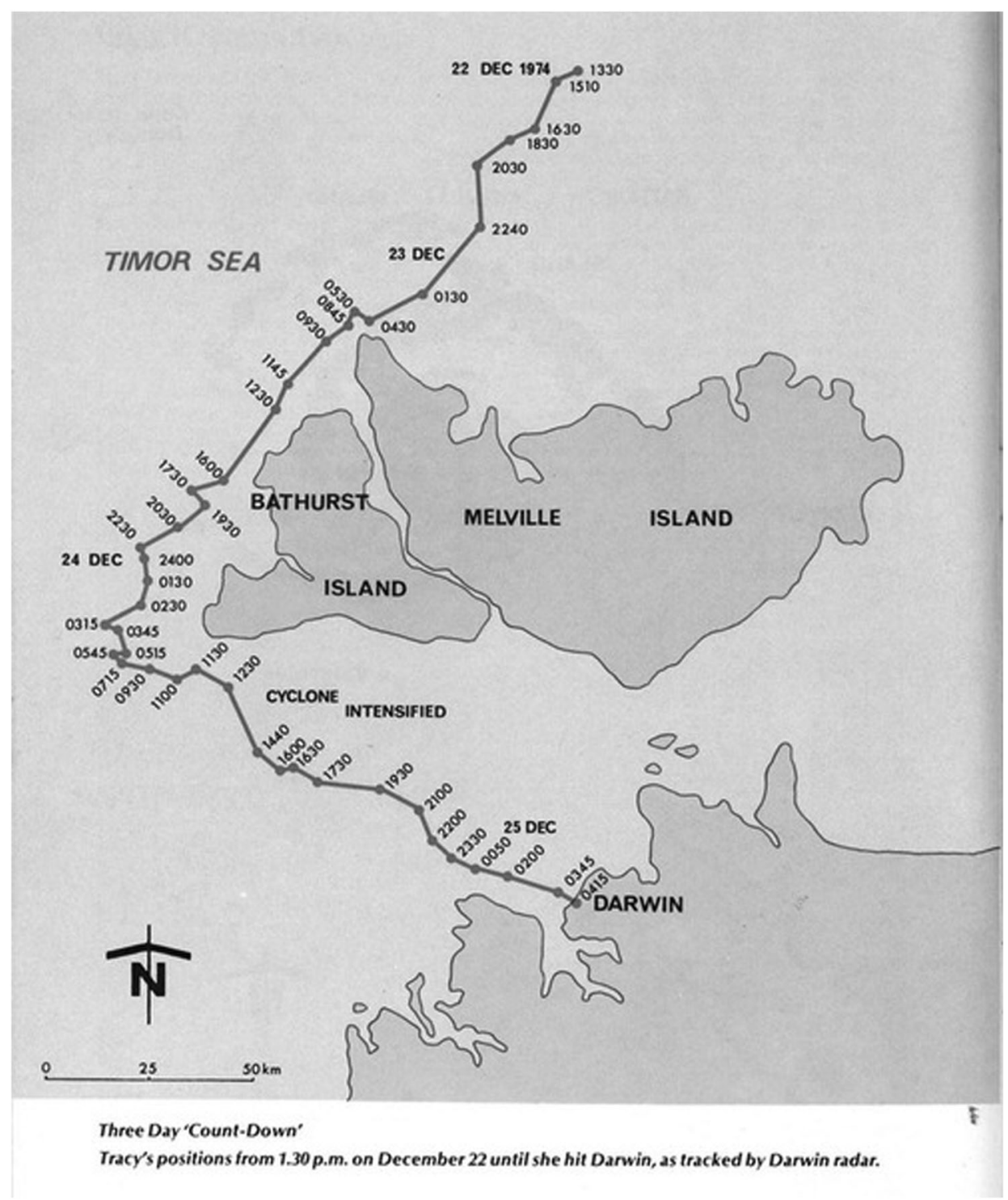

Figure 2. Track of Cyclone Tracy in Northern Australia, December 1974. Source: National Archives of Australia. Records about the Northern Territory. Gallery. Image 018. 
A multitude of factors have been and are still discussed as to why Darwin appears to have been largely unprepared (Australian Bureau of Meteorology, 2014; Cunningham, 2014) - even though some key institutions had made preparations. Many residents were accustomed to cyclone warnings, which had resulted in at best minor disruption, and most had not actually experienced a cyclone. There also could have been some complacency. A few weeks before Christmas, there had been warnings and preparations for Cyclone Selma which had turned out to be unnecessary (Australian Bureau of Meteorology, 2014). However, the major factor was almost certainly that it was Christmas Eve and people were too preoccupied with seasonal festivities to make cyclone preparations a priority (Australian Bureau of Meteorology, 2014; Cunningham, 2014).

In 1974 most of the city's housing was of light construction elevated to take advantage of any breezes, to cool down quickly at night, and to provide dry and shaded underhouse space. This style of building, which is widespread throughout the Australian tropics, is particularly vulnerable to high winds. The results was that over $80 \%$ of the housing stock was destroyed or severely damaged (AIDR (Australian Institute for Disaster Resilience), 2020) (Figure 3). Many government and major private sector buildings were engineered structures, which generally suffered much less damage than the housing sector. Nevertheless, some of these buildings were destroyed or badly damaged, including buildings built of stone and brick, and modern brick buildings were not spared. Even though many continued to be used after the cyclone, such as the hospital and nurses quarters, we suspect that today they would be seen as unfit for use, at least until inspected and certified, which would make them unavailable for immediate response and relief. This reflects the increasing risk aversion in all areas of government, including emergency management (Novak \& Glover, 2019). Throughout the city most infrastructure, communications, electricity, transport, etc, was non-functional, along with many functions of government and commerce (AIDR (Australian Institute for Disaster Resilience), 2020; Stretton, 1975). Seventy one people lost their lives and there were about 650 recorded injuries (note that different sources provide slightly different figures). Total damages approach 7 billion AUD in today's dollars (AIDR (Australian Institute for Disaster Resilience), 2020). This does not include the extensive destruction of vegetation (and temporary loss of ecosystem services) in and around Darwin. Suburban Darwin was largely devoid of trees, shrubs and birds after the cyclone. A major impact was the loss of communication within the city and with the rest of the world.

The event ranks as one of Australia's costliest disasters. It remains unusual in that the city's residential sector was largely destroyed, and the bulk of the population evacuated with little prospect of immediate return. As a result of the cyclone, changes after the event included the introduction by the Red Cross of a system to trace individuals impacted by disasters, and new cyclone building regulations.

\section{Mobilisation of the community of Darwin: adaptability and informality}

\subsection{Limited telecommunications}

In 1974 communication was restricted to land-line phones, radio and telegrams. Broadcast TV was also used to inform people. There was no internet, social media, or mobile phones, and it can seem difficult to imagine how rapid communication could occur. 


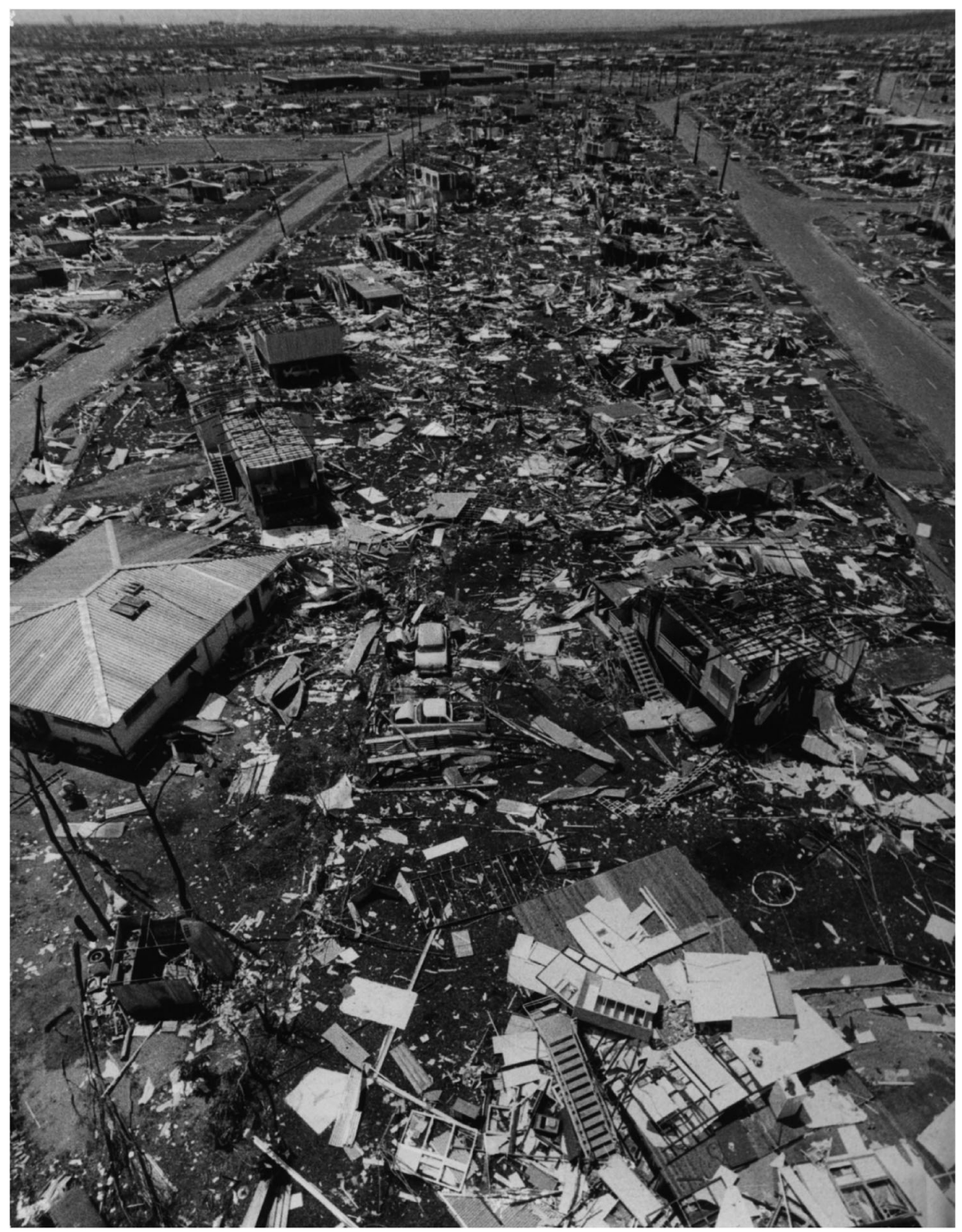

Figure 3. Houses in Darwin after Cyclone Tracy 1974. Source: Northern Territory Library: Cyclone Tracy. Darwin. Creative Commons Attribution license 4.0.

For a few hours after impact there was no communication between Darwin and the rest of Australia (Stretton, 1975, 1977). Early on Christmas Day people in Southern Australia heard that communication with Darwin had been lost when the city was hit by Cyclone Tracy and there was presumed to be extensive damage.

Although official communications were no longer operational, news of the cyclone was passed on within hours. Amateur radio operators ${ }^{1}$ were able to establish communication, and very quickly an ad hoc network was established across the country. This network was 
coordinated by Melbourne D24 police, and provided message services to metropolitan and regional cities across Australia. By mid-morning on Christmas day technicians had established a radio link on board a vessel in Darwin Harbour. For five days this handled official communications using machine morse code (https://en.wikipedia.org/wiki/ Cyclone_Tracy). Some sources mention that a temporary microwave link to Mt Isa (a mining town in Queensland) had been set up especially to relay the Queen's Christmas message to Darwin, and as this link remained functional it was used to get the first media reports out. By mid-morning limited communications established that the city had been largely destroyed and this was reported in Australian media. (See section 4.1; Supplementary material.) However, it was many days before the phone system was fully operational. People had to queue for hours to make brief calls to their families elsewhere in Australia on specially installed public phones.

The local $A B C$ (a national government broadcasting network) radio station in Darwin was able to get back on air quickly and broadcast continuously as the only functioning broadcast media for weeks after the cyclone.

\subsection{Community mobilisation}

The complete absence of (both internal and external) tele-communication was very unusual, but this does not appear to have overly hampered the response of the local community, or the official emergency management system. Due to Darwin's isolation, the community had to get maximum usage out of the local resources. It is long established that local people are usually the initial responders in a disaster because they are at the scene where immediate rescue and relief are required, and because it takes time for the official system to arrive (Scanlon et al., 2014; Whittaker et al., 2015).

By 0700h on Christmas Day the winds had died down. Before daylight, many families had thought they were the anomaly, in that it was only their house that was destroyed. But as people emerged from shelter it became clear that there was mass destruction of buildings and infrastructure. It was at this point that informal volunteers, including people with specific expertise, emerged. Dispersion of aid began with those who were physically injured and required medical treatment. Doctors travelled from house to house providing immediate treatment on the spot while those who managed to salvage cars drove the injured to hospital (Australian Bureau of Meteorology, 2014; Glenys, 2004) and makeshift first-aid posts. The hospital was badly damaged but continued to function and staff and volunteers made their way there to work, even though some had lost everything. As it was Christmas Day many of these people were acting in a voluntary capacity highlighting the permeable boundary between volunteering and paid work. Some who operated heavy machinery set about moving rubble to provide a clear pathway to the hospital, and to ad hoc. relief centres typically schools and community centres (Australian Bureau of Meteorology, 2014; Glenys, 2004). Locals at these centres began recovering food and donating clothes to those in need. With no sewerage, emergent (local) volunteers dug pit latrines- these areas of local activity became hubs for support and resources. This was complemented by local and interstate volunteers from formal organisations such as the Red Cross and faith groups who were active from day one. A supermarket, medical centre, clothing store and church all offered free support and resources to the community - providing practical and emotional support in the first 
days of the recovery process (When Will the Birds Return? 1975) -perhaps a reason why morale was described by many at the time as very positive.

Formal organisations were also active and flexible: for example, 208 members of the Northern Territory Police Force were active in the community on Christmas day 1974 (Cunningham, 2012; Stretton, 1975). In a recent interview a retired police officer recalled that the police increased their capacity by having each officer work with two community members. Bicycle riders set up a 'running telephone' between the airport and the city, relaying important information throughout the day (Australian Bureau of Meteorology, 2014; NewComAu, 2014). These and other activities appear to have been self-organised by people with the necessary skills, or the result of emergent leadership. Emergent volunteers often self-organise without clear leadership structures, which in turn can make it more difficult to engage with formal systems (Scanlon et al., 2014; Strandh \& Eklund, 2017). Formal systems tend to seek structures and entry points that replicate their own (Strandh \& Eklund, 2017).

The Darwin Hospital had limited electricity and much of the structure was destroyed or damaged. The nurses' accommodation was also damaged but continued to be used. Some preparations had been made for the cyclone which helped ensure access to medical supplies, and staff of all levels and categories made their way to the hospital and were immediately occupied treating the injured. On that day there were 500 outpatients and 129 acute patients (Vanovac, 2014). Examining the accounts of the time from all levels of hospital staff, many of whom were in a volunteering capacity, it is clear that some staff found the experience very stressful, but continued to work. A surgical relief team arrived by air late on Christmas day. Some government and NGO staff, as well as some informal volunteers, worked continuously for over $24 \mathrm{~h}$ and for many days had little sleep. This can lead to poor decision-making and avoidable errors. Unfortunately sleep deprivation remains common among Australian emergency managers (Sleep Health Foundation, 2020).

\subsection{Mass evacuation}

Despite the lack of communication and social media, Major General Stretton, the newly appointed Director General of the NDO, arrived in Darwin the same day as the cyclone - December 25 (Stretton, 1975) on the first flight into the city post impact. On the day of his arrival, General Stretton convened two meetings of the local emergency management committee - so speed of response was not at issue. The second meeting concluded with a decision to evacuate all non-essential personnel (Stretton, 1975, 1977) on the advice of the NT Director of Health, prioritising women and children, and those who were injured (Table 1, Figure 4). With the possibility of disease and a shortage of

Table 1. Priorities for evacuation. Priority 1 was evacuated first.

\begin{tabular}{ll}
\hline Priority & \multicolumn{1}{c}{ Criteria } \\
\hline Priority 1 & Pregnant women/sick \& injured \\
Priority 2 & Women and children \\
Priority 3 & Elderly people \\
Priority 4 & Married couples \\
Priority 5 & Single people \\
\hline
\end{tabular}




\section{Decrease of Population by Evacuation}

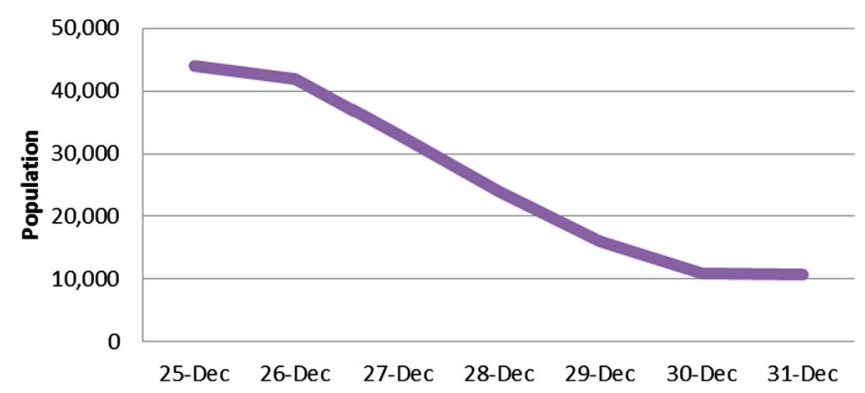

Figure 4. Population VS time graph. Showing a major decrease in Darwin's population due to evacuation by road and air.

potable water, it was thought to be a preventive for what could have developed into a humanitarian crisis. The airport had ceased to function due to wind damage to its equipment and buildings and the destruction of aircraft. Despite this, limited flights with essential personnel and equipment were able to operate, and the airport was made functional enough for the mass evacuation of Darwin to begin early on the $27^{\text {th }}$ December, a little over a day after the decision to evacuate.

The rapid mass evacuation has been critisized on two main grounds. One is that splitting up families was policy (see Table 1). The other is that despite the destruction, key infrastructure was restored to most parts of the city within days. Power was restored fairly quickly and medical facilities, which operated throughout the crisis, were reinforced with staff and supplies from the rest of the country. The phone system took longer to get back to normal, resulting in anxious waits as the fate of many was not known to their families elsewhere in Australia for days.

\subsection{Mobilisation of the nation: flexible rapid response by civil society and government}

By the middle of Christmas Day Australians were becoming aware that Darwin had been destroyed by Cyclone Tracy, and that there were many dead and injured. This triggered rapid national mobilisation of support in the form of donations, and volunteers with all types of expertise (ABC News, 2016; Trove, 2016a, 2016b). However, details were very slow to emerge and there was limited communication between individuals in Darwin and their families in the south of the country. As a result, even though aid and support of all forms flowed very rapidly to the city - with a striking lack of bureaucratic delay for many it was days before they knew the fate of family members. Some individuals with expertise they felt the city needed reported hitching rides on official aricraft.

The early hours of Boxing Day saw the arrival of interstate reinforcements for the Red Cross, which accordingly became responsible for feeding, clothing and general registration of those requiring assistance (Trove, 2016). Prior to this, local people on their own initiative had set up food and first-aid posts using school buildings, and there was much sharing of clothing and food. Red Cross members from Western Australia set up 
a first-aid post, with additional local volunteers, they worked for up to 20-30 h shifts to support those left homeless and injured ("They survived ...", 1975; Penden, 2014).

The rapid response seen within Darwin was replicated in across Australian communities and charities. Many Australian communities set up appeals to aid what was going to be a long recovery, as it became clear that this would involve reconstruction of most of the city. As news of the extent of the cyclone's impact spread, donations surged. Starting with the Melbourne Boxing Day cricket match, sporting events organised collections; state governments and media set up appeals, as did many communities, workplaces and other organisations. A notable contribution was from the residents of Alice Springs, who had direct contact with most of the 10000 evacuees leaving Darwin by road, as those driving south had to pass through the town. An appeal set up by service clubs in Alice Springs, saw a total of $\$ 105,000$ (1974 dollars - worth about ten times this amount in 2020) raised within just $31 \mathrm{~h}$. The town's residents also responded by providing emergency accommodation for evacuees, and food and petrol for those going on to Adelaide ( $A B C$ News, 2016; Trove, 2016c) - a 3000kms journey from Darwin. Through the Northern territory the road was mostly a single lane of bitumen, but south of the border with South Australia it was an unsurfaced track cut into the soil. By the end of the day after the cyclone struck, December 26 or Boxing Day, there appeared to be an exponential growth in both charity donations and the spread of detailed news about the state of Darwin. Every corner of the country seemed to be involved with supporting Darwin and its evacuees, and by the 27th December, global media were reporting in detail on the cyclone.

The Government focus in the following days was the restoration of Darwin's essential services and the evacuation of the city. There was considerable volunteer assistance from across Australia with all types of services and restoration.

It is not our purpose to delve into whether the decision on mass evacuation was correct. The authorities argued that as most housing had been destroyed and there were or soon would be food and other shortages, and the possibility of disease, evacuation was the only option. However, the rapid mandatory nature of the evacuation as if the people needed to flee an advancing enemy has led to some criticisms. It was probably not a good idea to split up families with, in some cases, children being sent south separately, and family members having difficulty locating each other (Qantas Travel Insider ). Also while many wanted to leave or were being urged to go by families, some felt forced to go against their will. People reported being unable to stay for funerals of family members, and pets were reportedly summarily shot by police. These are examples of resentments held by people decades later.

Aircraft for the evacuation were provided at almost no-notice by the military and Australian airlines, in particular Qantas, with one flight setting a record for the number of people carried on a Boeing 747with 674 passengers and 23 crew (Qantas Travel Insider, 2020). The population was reduced to just over 10,000 through evacuation by air and road (Figure 1). About 25,000 were evacuated by these free flights. Planes arrived in southern capitals, and local people volunteered to provide accommodation and support. The Red Cross started its Australian disaster registration and tracing system at this time, which remains in use for major emergencies.

Rapid mobilisation of Australian towns was essential to ensure that they had the resources and services to provide for the incoming evacuees. Emergency 
accommodation, food and health care were the basic needs, but there was also the issue of employment and longer term accommodation for many who no longer had a house in Darwin. The evacuees needed and received essential material support, but there may have been gaps where mental health was concerned for both evacuees and those helping them. For some these issues continue today (Carson, 2008; Facebook Group, n.d). This was the first large scale Australian evacuation since WWII. Another unique aspect was that evacuees had to travel $2000-3000 \mathrm{kms}$, so there was little prospect of them returning to salvage possessions or check on animals or buildings. A permit system to control entry to the city also prevented evacuaees from early return to the city. It is estimated that about $60 \%$ did not return (Carson, 2008). This in turn may have exacerbated the mental strain of the cyclone (Chamberlain et al., 1981). There was however, no shortage of empathy and material support. One problem with post-Tracy support, which is typical of many disasters, is the flood of inappropriate donations, for example of warm clothes, food and items past their use-by dates - which continues to be a problem in major disasters (Islam et al., 2013; Trove, 2016b).

\section{Informal volunteering after Cyclone Tracy}

There was little or no hesitation among, at least much of, Darwin's population - and many others across Australia - to fill the gaps in key services and importantly to take the lead in in meeting the immediate needs of those impacted by the cyclone. It is important to note that much informal volunteering took place without obvious bureaucratic leadership and in the absence of telecommunications, let alone modern mobile communication.

Officials and official members of emergency related organisations were working alongside informal volunteers on a large scale. No complaints were found to have been made about the contribution of the emergent volunteers who encouraged the workings of a bigger community response. (This doesn't mean that there were no complaints, but it does mean that at the time they were relatively few and low key.) The head of the immediate relief phase, General Alan Stretton of NDO, gave strong praise to the community of Darwin and their ongoing work at the time of Tracy. Acting pragmatically to address critical needs, it was straightforward to bypass bureaucratic process which appears in this case to have resulted in successful outcomes (Stretton, 1977). The very substantial surge in capacity seemed often to be almost seamless between officials and the informal volunteers. At the time this was hardly remarked on within Darwin, and while there was much coverage of people helping out across the nation, the commentary was generally positive and supportive. The focus on the tasks at hand rather than normal official processes likely reflects the priorities of 1970s Australian society.

From the start of the response and initial recovery period, informal delegation took place. It appeared that people within the Darwin community knew their and other community members expertise and where they would be needed. This may be due to the relatively small population size, and that the majority of the workforce was employed by the federal government, and also in construction.

In all types of disasters, people from the affected communities - in the form of informal volunteers - emergent and extending - are usually the first on the scene, as was the case in Cyclone Tracy, simply because they are already present (Britton, 1991). Often, emergency services are not present because it takes time to get to the scene, they have 
other priorities, or are prevented by debris or other issues from going to where help is needed.

An apparently non-hierarchal structure or more properly network, independent of accreditation or employment status emerged to support immediate response and needs. This fits the idea which had strong currency at the time that Australia was an egalitarian society unless you were indigenous, although even here it has been argued that indigenous people played active roles after the cyclone with everyone else (see section above). This loose community structure became a foundation for the successful rapid mobilisation from the first few hours after Cyclone Tracy struck. Community members included doctors, local police officers, and military personnel, as well as the wide range of skills normally found in a community (Stretton, 1975). Emergent leaders, often simply people taking initiative, who could organise a school into a canteen or first aid post, were important is this mobilisation. People with special skills would use them for specific tasks (ABC News, 2016; Martin, 2014). Those who owned restaurants or worked in school canteens would cook batches of food for those in relief centres (Cunningham, 2014). There was also an imperative to cook food before, in the absence of refrigeration, it became unusable in the tropical heat. As a result people ate well in the days immediately after the cyclone usually employing a gas or wood BBQ as there was no electricity.

A feature of this successful organisation, was the re-emergence of Darwin as a temporary city, more like a camp, with few central service providers at first, apart from the hospital, and with informal volunteers attending to many basic needs, as well as NGOs and other groups operating out of damaged buildings or tents, all connected by 'runners' and people on bikes - in the absence of phones. Food was being given away as needed. Even though the majority of infrastructure was destroyed, resources appear to have been utilised in a pragmatic way. At this time in Australia, purchases were made by cash or cheques. In a disaster, people would run out of cash and many shops, in for example flood prone areas, were in the habit of accepting IOUs ('I owe you', through which the shop owner provided credit). Today, most purchases in Australia are cashless, but buying and selling now requires electricity and secure data transfer. The experience of New Orleans after Hurricane Katrina when people could not access their accounts for weeks is illustrative here, as are studies on food security showing that electricity is now essential for transactions, and for stocking and managing food stores, quite apart from refrigeration.

'Courage and smiles, it's tremendous' is a quote taken from When Will the Birds Return a documentary film of Darwin post-Tracy made immediately after the disaster (NewsComAu, 2014; When will the birds return?, 1975). This describes the willingness of many to aid those in need. Creating a surge in capacity for billeting evacuees throughout the country occurred within a day or two. Today, when organised by government evacuees are housed in hotels or evacuation centres rather than by individual households. However, there are now person-to-person temporary housing location systems operating through social media.

\section{The Cyclone Tracy emergency in the context of 1974 Australia}

Important attributes of the event examined in this paper, and in response to the questions posed at the start of the paper, are the rapid official and public response to an event thousands of kms away; the largely uncomplicated merging of official and unofficial expertise, 
and the mobilisation of the nation - all contributing to a massive surge in capacity to deal with the emergency and its immediate aftermath.

The material set out and discussed in this paper paints a fairly positive picture of a city in a catastrophe, of an emergency management system, and of the people of Australia. Our study focuses on the more or less spontaneous volunteering that occurred within Darwin and across Australia as a result of the cyclone, and its interactions with the formal or official system. We do not examine the response by the Natural Disasters Organisation (NDO) ${ }^{2}$, or the longer-term issues confronting the city. In considering the context of Australia in 1974, NDO was newly formed with an emergency management focus, but had just emerged from a war oriented civil defence focus, and state emergency services were on paper at least, still as much civil defence as emergency management.

It is important to appreciate that the response and the mass volunteering were not perfect. We found some complaints, and there were individuals who understandably could not manage the stress, could not work well under pressure, or who found the changed expectations, roles or relationships immediately after impact, challenging, including some who worked for exceptionally long hours (an ongoing issue for emergency responders of all types). Support and counselling services existed but were very limited by today's standards. There were also local concerns about some interstate groups, in particular police. There were runours about the cyclone reforming. In addition, there were concerns with the mass evacuation and associated tracing issues (Trove, 2016c). It is also likely that the media and officials emphasised the positive aspects of a city and nation working to support those caught up in a major crisis, and did not allow complaints and antisocial behaviour to deflect them.

\section{How would we manage today?}

If a similar event occurred today, how would we manage? In seemingly complete contrast to 1974 most Australians have near perfect, universal communication, we have highly detailed real-time data on what people and infrastructure are doing, and our emergency management systems, training and planning are at a completely different level. Australian emergency management is almost unimaginably better trained, equipped, and informed, and have become more professionalised. We also have a policy agenda for community resilience and shared responsibility for emergencies across government and communities. We would quite reasonably expect to do much better, and to do it much more quickly.

But would we mobilise any quicker? Would we see an almost seamless merging or at least coalescing of the official and informal? And would we see general mobilisation of Australians in support?

Here we set out some issues, focusing on communications, informality (or put another way the professionalisation of the emergency management system, bureaucratic requirements and compliance), the space for civil society to operate, and our apparent tendency to focus on the negative. These are potential issues that, likely among others, could impede the ability for rapid whole of society capacity and response.

Instant continuous communication and social media - a theme of this analysis has been the speed of response by both officials and the whole of Australia. This occurred when 
there was virtually no communication out of Darwin. There was basic radio, including some Defence radio, and then a single phone line. Essentially the people of Darwin could not communicate with each other except face-to-face and could not communicate with anyone outside the city. However, it is hard to show that this slowed down response and relief. This is not to argue that social media and modern communications make no difference: we know that it can make a huge difference in many cases (see Stone et al. in this special issue), but we are not sure that in a Cyclone Tracy scenario today it would make a positive difference to the initial response. Today drones and remote sensing would be used to scan the affected areas, identify needs and help coordinate response, but in 1974 most areas had roads cleared rapidly and power restored within days. Social media would make a major difference in other ways however, for example many people did not know the fate of family members, as phone limitations meant that it took days for some to be able to make a call letting family know they were safe. Modern communications would also likely lead to more coverage of the event with consequently increased donations, including of inappropriate goods. The major national telco, Telstra, states that $99 \%$ of the Australian population is now covered by their mobile network (Telstra, 2019), and some 91 percent of Australian adults have smart phones (Deloitte, 2019). We are well adapted to instant communication often via video or multi-media. There are however digital divides in Australia: with remote rural areas, older people, and poorer households having less access to modern communication technology. The shift to on-line schooling during the Covid-19 crisis has dramatised these divides and shown how marginal essential internet access is for many Australians. Nevertheless, we are fully reliant on contemporary communications including for almost all transactions system controls, and it is not clear that we could function without it.

The formal emergency management system is now far more trained, professional and credentialed. It is also very concerned about legal and other liabilities, occupational safety issues, personal protective equipment, the need for police and other checks, etc, with a push to have some of the personal checks performed on a regular basis. The system is increasingly centralised and less flexible. These trends are not unique to emergency management, they reflect modern Australia, and are found across the volunteer and nonprofit sector. This raises at least two major issues: such detailed monitoring might not be fully compatible with liberal democracy; and many people are concerned with conflating their private lives with their interest in contributing to modern Australian society through volunteering. Perhaps paradoxically, as emergency management in Australia has become increasingly professional, credentialised, bureaucratised and compliance focused, it has also become more rigid and less able to switch operating modes. This is the so called 'rigidity trap' (Rogers, 2013). In routine emergencies the system has worked well in a command and control mode, but in large complex events, a facilitator mode is needed to draw on all society's resources for a desired end. This can all make use of non-affiliated volunteers slow and partial with many potential hurdles. Queensland through EV-CREW has a well-rehearsed system for handling such volunteers (McLennan et al., 2016). Nevertheless, these are pre-identified people who would work under the control of the official system. It can be argued that, although the picture varies considerably by locality, the emergency management system has all but lost its ability to allow citizens the space to work on their own communities with their own priorities during crises. There are some counter movements, such as the NSW State Emergency Services 
mobilisation model and Community Based Bushfire Management (CCBM) in the state of Victoria, although these do not involve emergent groups (see McLennan et al. in this special issue).

Related to this point, is our focus on compliance with a wide range of requirements. We do not argue that these requirements, which were largely absent in 1974, are not important and usually desirable. They typically include: health and safety, police checks, working with children checks, working with vulnerable people checks, safe food handling, currently correct personal protective equipment, procedures for handling potentially contaminated debris, etc, in addition to issues of insurance and legal liability. In addition, for community groups the range of financial requirements, including micro requirements on expenditure, can make it very difficult to operate. In specific circumstances as with biopathogens, some requirements are critical and life-saving such as appropriate protective equipment. However, some can constitute impediments to emergent volunteering and especially to the merging of formal and informal systems. At some point, in some overwhelming crises, these procedures could become a major impediment to the main aim of saving lives, livelihoods and property. Again, this is not arguing that they are unnecessary, but that in some cases priorities, and the operational model, need to shift. A formal declaration of a state of emergency, can change aspects of this situation, for example, by ensuring that all volunteers, formal and informal, are insured.

Another point concerns civil society - that is the Third Sector: 'the space for collective action around shared interests, purposes and values, generally distinct from government and commercial for-profit actors.' (World Health Organization, 2020). In 1970s Australia civil society was very active, would self-organise to get things done, and work closely with official systems, including the police and other uniformed services [eg see (Trove, 2016b)]. It is clear from the Cyclone Tracy study presented here, that many people would take initiative to do what they thought was needed, in the absence of an official resilience narrative (although there were narratives about self-reliance). This includes lay people as well as those with specific expertise and training. Spontaneous volunteering was strong and in the Darwin context generally effective; and seemed to generally work well alongside official organisations and structures. (A counter argument could be that many people turn up to help with bushfires with seriously inappropriate clothing.)

At one level we can still see some of this - the EV CREW example mentioned above and similar efforts to have volunteers pre-identified, and there are many examples of bystanders taking life saving actions (McLennan et al., 2016). But civil society space in Australia has shrunk as Government and the private sector (often through outsourcing of previously government services), have expanded, and as government control over many details of people's lives has increased. This is seen most explicitly in the increasing restrictions, codes of conduct and criminalisation of many activities traditionally undertaken by citizens, especially by CSOs and media in the name of various types of confidentiality and security (Rogers, 2013; Star, 2018; UN Information Centre, 2016). The national push for a more resilient society could be seen as a push for greater civil society activity (National Strategy for Disaster Resilience, 2011). But a number of senior officials in the resilient scene have stated that for this to occur, governments need to role back some of their power - and this has yet to happen (Comrie, 2013).

As mentioned, the response and relief activities post Tracy were certainly not perfect. We have focused on the positive and have not gone into the problems that arose - 
although we emphasise that at the time the problems did not derail the response, and received relatively little media coverage. Now in an environment chasing zero organisational risk and frequent knee jerk reaction, fed by a rapid media cycle and unforgiving real-time scrutiny, some of the relatively minor (in the context of the detruction) issues that occurred after Tracy would likely deflect attention and focus from the overall positive picture of cooperation and mutual support. For example, there were some reported instances of looting and of people taking advantage of the free support provided by people on the Sturt Highway leading south from Darwin. It has been orthodoxy that there is no looting in disasters and that people don't exploit disaster relief; this may generally be the case, but Handmer (2007) argues that while unusual it does occur. There were accounts of police unnecessarily shooting pets, and of traumatised people continuing to work. Now, media, politicians and officials would likely shift their focus to dealing publicly with these unfortunate incidents, possibly giving them much public profile to the detriment of the main task, and imposing additional barriers to the smooth flow of response and relief. We are also much more entitled, likely to hold widely divergent views, and more prone to criticise about the relatively trivial.

In conclusion, to manage surge capacity well the formal emergency management system needs to either have the capacity itself, or to be able to facilitate and work with civil society - as happened following Cyclone Tracy. Today we have many advantages of technology, communications, knowledge and emergency management systems, as well as a strong national narrative in Australia about shared responsibility and community resilience. We could reasonably expect to do much better than in 1974. However, in various ways and guises governments are now more controlling, emergency management is under greater scrutiny especially through public enquiries, and people's expectations of government are also often higher. In 'normal' emergencies this does not result in problems, but in large complex emergencies, these changes in government and society create barriers to informal volunteering and large scale community mobilisation. Governments want resilient self-reliant communities, but only on their own terms - something that is not restricted to Australia (Raisio et al., 2019). Attempts to expand the capacity of the Australian emergency management system are today resulting in increasing use of Australian and overseas military forces and official emergency responders. An alternative approach is in Scanlon (Scanlon et al., 2014) who set out a model developed in part of the Netherlands dedicated to the integration of civil society with formal emergency responders. In this Amsterdam Amstelland model, all emergency responders are explicitly allowed to accept assistance from ordinary citizens and organisations in emergency response. This makes it clear that cooperating with citizens and allowing citizen response is a (new) professional standard (Scanlon et al., 2014). There are some moves in this direction in Australia, for example the NSW State Emergency Services community mobilisation model under which SES members can be grouped with community volunteers but such moves are very partial. Resolving the tension between people's need to help in emergencies with government's need to control, ensure compliance with a range of regulations, and avoid blame, is a major challenge with surge capacity in Australia and elsewhere. 


\section{Notes}

1. Also know as "Ham radio" - refers to the organised use of radio frequencies for private noncommercial purposes: eg recreation, personal messages, experimentation, self-training and emergency communication.

2. We recognise that today the term "natural disaster" is seen as incorrectly implying a lack of human agency in creating disasters. It has been suggested that the name Natural Disasters Organisation was a typographical error, and "Natural" was meant to be "National". In any case "Natural" emphasised the change in focus from a war related civil defence to the everyday emergencies confronting Australians - even though it remained located in the Department of Defence.

\section{Acknowledgements}

The authors thank the Bushfire \& Natural Hazards Cooperative Research Centre and RMIT University for supporting this research and writing. Our appreciation goes to Blythe McLennan for insightful comments and support.

\section{Disclosure statement}

No potential conflict of interest was reported by the author(s).

\section{Funding}

This work was supported by the Bushfire and Natural Hazards Cooperative Research Centre Project: Out of Uniform: building community resilience through non-traditional emergency volunteering (2014-2017). https://www.bnhcrc.com.au/research/communityresilience.

\section{References}

ABC News. (2016). Cyclone Tracy remembered: Alice Springs inundated with 5,000 refugees from Darwin - ABC News (Australian Broadcasting Corporation). [ONLINE] Retrieved May 6, 2016, from http://www.abc.net.au/news/2014-12-16/alice-springs-residents-remember-helpingcyclone-tracy-refugees/5969168

AIDR. (2017). Communities Responding to Disasters: Planning for Spontaneous Volunteers. Handbook 12.

AIDR (Australian Institute for Disaster Resilience). (2020). Knowledge Hub Retrieved September 8, 2020, from https://knowledge.aidr.org.au/resources/cyclone-cyclone-tracy-darwin/

Austin, L., \& O'Neill, G. (2015). The state of surge capacity in the humanitarian sector 2015. Action Aid International. Retrieved July 10, 2020, from https://start-network.app.box.com/s/8ij8s53thd7fza 1yss3z1rsf81unz78t

Australian Bureau of Meteorology. (2014). Remembering cyclone Tracy: Lessons from a 'perfect storm' 10 Dec 2014. Retrieved September 8, 2020, from http://media.bom.gov.au/social/blog/ 625/remembering-cyclone-tracy-lessons-from-a-perfect-storm/

Britton, N. R. (1991). Permanent disaster volunteers: Where do they fit? Nonprofit and Voluntary Sector Quarterly, 20(4), 395-414. http://nvs.sagepub.com/content/20/4/395.abstract. page 397. https://doi.org/10.1177/089976409102000404

Carson, D. (2008). Demographic change sin the Northern Territory following Cyclone Tracy. Pop Studies Research Brief. ISSUE Number 2008018. Retrieved September 12, 2020, from https:// www.cdu.edu.au/sites/default/files/research-brief-2008-18.pdf

Carson, D. (2011). Political economy, demography and development in Australia's Northern Territory. The Canadian Geographer, 55(2). https://doi.org/10.1111/j.1541-0064.2010.00321.x 
Chamberlain, E. R., Doube, L., Milne, G., Rolls, M., \& Western, J. S. (1981). The experience of Cyclone Tracy. AGPS.

Clothing appeal postponed - Trove. (2016). 08 Jan 1975 - Clothing appeal postponed - Trove. [ONLINE] Retrieved April 22, 2016, from:http://trove.nla.gov.au/newspaper/article/110632011? searchTerm=alice\%20springs\&searchLimits=dateFrom $=1975-01-01|| \mid$ dateTo=1975-01-31

Comrie, N. (2013). Final Report VBFIM (Victorian Bushfires Implementation Monitor). Melbourne.

Cunningham, S. (2012). Disappeared: This disaster was not televised [Human reactions to cyclone Tracy. Paper in: Surviving. Schultz, Julianne (ed.).]. Griffith Review, 35, 88.

Cunningham, S. (2014). WARNING, The story of cyclone Tracy. Text Publishing.

Deloitte. (2019). Mobile Consumer Survey. Retrieved July 10, 2020, from https://www2.deloitte.com/ au/en/pages/technology-media-and-telecommunications/articles/mobile-consumer-survey. html\#: :text=91\%25\%20of\%20Australians\%20have\%20a,from\%20three\%20years\%20in\%202017

Dionisio, M. R., \& Pawson, E. (2016). Building resilience through post-disaster community Projects: Responses to the 2010 and 2011 Christchurch Earthquakes and 2011 Tōhoku Tsunami. Australasian Journal of Disaster and Trauma Studies, Retrieved June 7, 2020, from http://trauma. massey.ac.nz/issues/2016-2/AJDTS_20-2_Dionisio.pdf

Dynes, R., \& Quarantelli, E. L. (1968). Group behavior under stress: A required convergence of organizational and collective behavior perspectives. Sociology and Social Research, 52, 416-429.

Facebook group. "Cyclone Tracy survivors" with over 4000 members. There was much activity at the $40^{\text {th }}$ anniversary in 2014.

Glenys, D. (2004). Cyclone Tracy- An Unforgettable Christmas. Museum \& Art Gallery of the Northern Territory.

Handmer, J. (2006). American exceptionalism or universal lesson: The implications of Hurricane Katrina for Australia. Australian Journal of Emergency Management, 21(1), 29-42.

Handmer, J. (2007). Have disaster myths become legends? Natural Hazards Observer, 31(6), 4-5.

Handmer, J., \& Dovers, S. (2013). Handbook of disaster policies and institutions: Improving emergency management and climate change adaptation (2nd ed.). Taylor and Francis.

Handmer, J., Ladds, M., \& Magee, L. (2018). Updating the costs of disasters in Australia - 1967-2013. Australian Journal of Emergency Management, 33(2).

Haynes, K., Bird, D. K., Carson, D., Larkin, S., \& Mason, M. S. (2011). Institutional response and Indigenous experiences of Cyclone Tracy. National Climate Change Adaptation Research Facility. Gold Coast, Qld.

Hellyer, M. (2020). The Australian Defence Force's domestic role (part 1): How much does it do? ASPI, Canberra.

Insurance Council of Australia. (2019). Severe weather in a changing climate. IAG in collaboration with the US National Center for Atmospheric Research (NCAR). (Page 19). https://doi.org/10.5065/nx7j0s96

Islam, M., Dolan, K., Heggestuen, J., Nordenson, A., \& Vande Vate, J. (2013). Who is responsible for the second disaster? Stanford Social Innovation Review. July 29. Retrieved April 6, 2020, from https:// ssir.org/articles/entry/who_is_responsible_for_the_second_disaster

Jones, T. G. (2005). The Chinese in the Northern Territory. CDU Press.

Liston, G., \& La Canna, X. (2014). Cyclone Tracy: Aboriginal people foresaw 'bad event' in Darwin. https://www.abc.net.au/news/2014-12-25/cyclone-tracy-warning-to-aboriginal-people-to-leavedarwin/5987974

Martin, K. (2014). Remembering Cyclone Tracy. News.com. Retrieved May 10, 2018, from http:// www.news.com.au/lifestyle/real-life/true-stories/remembering-cyclone-tracy-red-cross-workersrecall-storm-chaos-and-devastation-in-darwin-40-years-on/news-story/ 1 f5c4bb96c5abc80bd8d3293ac456989

McLennan, B., Molloy, J., Whittaker, J., \& Handmer, J. (2016). Centralised coordination of spontaneous emergency volunteers: The EV CREW model. The Australian Journal of Emergency Management, 31(1), 24-30.

National Strategy for Disaster Resilience. (2011). Council of Australian Governments. Canberra. 
NewsComAu. (2014). Darwin doctor remembers Cyclone Tracy. [online] Retrieved February 23, 2018, from http://www.news.com.au/national/breaking-news/darwin-doctor-remembers-cyclonetracy/news-story/077eee1a025033c0f43823063548a165

Novak, B., \& Glover, R. (2019). Today's problems, yesterday's toolkit. ANZOG. https://apo.org.au/ sites/default/files/resource-files/2019-08/apo-nid253231.pdf See also: Retrieved September 8, 2020, from https://www.afr.com/politics/federal/creeping-crisis-of-risk-aversion-in-the-publicservice-20190813-p52gm9

Penden, L. (2014). https://www.ntnews.com.au/news/northern-territory/cyclone-tracy-survivorsstory/news-story/cc750cf7c568c31f7e56750c1e5ebbc3

Qantas Travel Insider. https://www.qantas.com/travelinsider/en/trending/top-100-guide/qantascentenary-history-community-spirit-cyclone-tracy-bushfire.html\#: :text=In\%201974\%20Qantas \%20made\%20history,on\%20board\%20a\%20Boeing\%20747

Quarantelli H. 1998. Major criteria for judging disaster planning and managing their applicability in developing countries. Retrieved April 5, 2019, from http://udspace.udel.edu/handle/19716/286. UD DRC

Raisio, H., Puustinen, A., Norri-Sederholm, T., \& Jalava, J. (2019). Those who agree to play on our terms will be taken in": A qualitative study on the perceptions of public authorities and NGO representatives regarding self-organizing fourth-sector activity. Public Administration Quarterly, 43, 4-44. Retrieved September 14, 2020, from http://urn.fi/URN:NBN:fi-fe202001172545

Rogers, P. (2013). The rigidity trap in global resilience: Neoliberalisation through principles, standards, and Benchmarks. Globalizations, 10(3), 383-395. https://doi.org/10.1080/14747731.2013. 787834

Scanlon, J., Helsloot, I., \& Groenendaal, J. (2014). Putting it all together: Integrating ordinary people into emergency response. International Journal of Mass Emergencies and Disasters, 32(1), 43-63. http://www.ijmed.org/articles/649/

Sleep Health Foundation. (2020). Sleep health for emergency services personnel. Retrieved May 2, 2020, from https://www.sleephealthfoundation.org.au/sleep-health-for-emergency-servicespersonnel.html

Star, C. (2018). Silencing Australian Civil Society: the Howard Legacy and the Abbott Government's Remaking of Australian Democracy. The Policy Space. Retrieved July 10, 2020, from https://www. thepolicyspace.com.au/2018/10/274-silencing-australian-civil-society-the-howard-legacy-andthe-abbott-governments-remaking-of-australian-democracy

Strandh, V., \& Eklund, N. (2017). Emergent groups in disaster research: Varieties of scientific observation over time and across studies of nine natural disasters. $J$ of Contingencies and Crisis Management, 26(3). https://doi.org/10.1111/1468-5973.12199

Stretton, A. (1975). Darwin Disaster: Cyclone Tracy, Report by Director-General, Natural Disasters Organisation (NDO) on the Darwin Relief Operations 25 December 1974. NDO, Canberra.

Stretton, A. (1977). The furious days: The relief of Darwin. Sun Books.

Taylor, A., \& Carson, D. (2018). Population change in the Northern Territory. Population Studies Research Brief \#2009032. Cdu.edu.au. (2018). [online] Retrieved February 22, 2018, from https://www.cdu.edu.au/sites/default/files/research-brief-2008-29.pdf

Telstra. (2019). Telstra mobile coverage explained. Retrieved July 10, 2020, from https://www. whistleout.com.au/MobilePhones/Guides/Telstra-mobile-network-coverage\#: :text=While\% 20Telstra's\%20full\%20network\%20reaches,reaches\%2098.8\%25\%20of\%20the\%20population

"They survived ..." (1975). Australian Women's Weekly (Wednesday 19th February 1975) 42(33).

Trove. (2016a). 02 Jan (1975) - THE DARWIN CYCLONE - Trove. [ONLINE] Retrieved May 6, 2016, from http ://trove.nla.gov.au/newspaper/article/110631249 ?searchTerm=cyclone\%20tracy\%20alice\% 20springs\&searchLimits $=$

Trove. (2016b). 28 Dec 1974 -c - Trove. [ONLINE] Retrieved May 5, 2016, from http://trove.nla.gov.au/ newspaper/article/110794225?searchTerm =cyclone\%20tracy\%20ACT\%20centre\&searchLimits=

Trove. (2016c). 30 Dec 1974 - THE DARWIN CYCLONE DISASTER People of Alice give $\$ 105,000$ Trove. [ONLINE] Retrieved April 28, 2016, from http://trove.nla.gov.au/newspaper/article/ 110794464 ? searchTerm=cyclone\%20tracy\%20alice\%20springs\&searchLimits= 
Twigg, J., \& Mosel, I. (2017). Emergent groups and spontaneous volunteers in urban disaster response. Environment and Urbanization. https://doi.org/10.1177/0956247817721413

UN Information Centre. (2016). Australian Government must re-build trust of civil society - UN human rights expert. UN Information Centre, Canberra. Retrieved July 6, 2020, from. https://un. org.au/2016/10/18/australian-government-must-re-build-trust-of-civil-society-un-human-rightsexpert/

Vanovac, N. (2014). Darwin doctor remembers Cyclone Tracy. [online] Retrieved February 23, 2018, from http://www.news.com.au/national/breaking-news/darwin-doctor-remembers-cyclonetracy/news-story/077eee1a025033c0f43823063548a165

When Will the Birds Return? (1975). [online] NFSA Online Shop. Retrieved February 23, 2018, from http://shop.nfsa.gov.au/when-will-the-birds-return

Whittaker, J., McLennan, B. J., \& Handmer, J. (2015). A review of informal volunteerism in emergencies and disasters: Definition, opportunities and challenges. International Journal of Disaster Risk Reduction, 13, 358-368. http://www.sciencedirect.com/science/article/pii/S2212420915300388

World Health Organization. (2020). Social determinants of health. Retrieved July 3, 2020, from https://www.who.int/social_determinants/themes/civilsociety/en/ 